\title{
SEROPREVALENCE OF ANTIBODIES TO VARICELLA- ZOSTER VIRUS IN MADRID (SPAIN) IN THE ABSENCE OF VACCINATION
}

\author{
Napoleon Perez-Farinos ${ }^{1}$, Luis Garcia-Comas ${ }^{1}$, Rosa Ramirez-Fernandez ${ }^{1}$, Juan-Carlos Sanz ${ }^{2}$, \\ Dolores Barranco ${ }^{3}$, Cristina Garcia-Fernandez ${ }^{1}$, Maria Ordobas ${ }^{1}$ \\ ${ }^{1}$ Epidemiology Department. Madrid Public Health Institute. Madrid, Spain \\ ${ }^{2}$ Public Health Regional Laboratory. Madrid Public Health Institute. Madrid, Spain \\ ${ }^{3}$ Disease Prevention Department. Madrid Public Health Institute. Madrid, Spain
}

\section{SUMMARY}

Objective: to ascertain the seroprevalence of antibodies to varicella-zoster virus in the Madrid population prior to the introduction of vaccination.

Study design: Cross-sectional antibody seroprevalence study.

Methods: Population: persons aged 2 to 40 years in Madrid. Field work: September 1999 to April 2000. Data were collected on demographic and socio-economic variables and on a number of exposures. IgG antibodies were determined using Enzyme Linked ImmunoSorbent Assay (ELISA), and antibody prevalence broken down by age group. Logistic regression was used to analyse the association between the presence of antibodies and the respective study variables. The results were compared against those of an earlier seroprevalence survey in Madrid (1993).

Results: A total of 2,131 subjects were included, with a non-response rate of $20.4 \%$. Antibody prevalence was estimated at $90.2 \%$; the $90 \%$ mark was reached at 11 years of age and almost $100 \%$ of adults presented with antibodies. In the case of children, school attendance associated with the presence of antibodies. No significant differences were observed vis-à-vis the results of the earlier survey.

Conclusions: The seroprevalence profile coincides with those of other Spanish regions and European countries, and remains stable over time. Antibody presence rises sharply in children from aged 2 years to adolescence. Further seroprevalence studies are called for to study the disease trend and assess preventive measures.

Key words: varicella zoster virus, seroepidemiologic studies, immunity, vaccination, public health policies

Address for correspondence: N. Perez-Farinos, Epidemiology Department, Madrid Public Health Institute. C/ Julian Camarillo 4B, 28037 Madrid, Spain. E-mail: napo@napo.jazztel.es

\section{INTRODUCTION}

Varicella-zoster (VZV) virus belongs to the herpes virus group and causes two diseases, i.e., varicella (chickenpox) and herpes zoster. Varicella is a highly contagious, typically childhood disease having a respiratory transmission route. It develops into vesicular exanthema and fever of generally benign progression, with a low rate of complications, which tend to be more frequent among adults (1). After the primary infection, VZV remains dormant in dorsal root ganglia and can be reactivated in $15 \%$ of the population, giving rise to the clinical features of herpes zoster. Herpes zoster is more frequent in persons of advanced age, and may leave sequelae, one of the most frequent of which is postherpetic neuralgia (2-4).

The introduction of universal varicella vaccination in children has been controversial, owing to its possible effects on the disease itself and on herpes zoster (5). Initially the vaccine was exclusively used on immunodepressed patients, but subsequently its general use was authorised in a number of countries, including Japan,
South Korea (6), the USA $(7,8)$, Sweden and Germany. Since its introduction in the USA, there has been a decrease in varicella incidence and mortality $(9,10)$. Here in Spain, it was first introduced in 1997 for high-risk patients. In 2005 it was included in the vaccination schedule for administration to adolescents, and in 2006 the Madrid Autonomous Region (MAR) included universal varicella vaccination in its systematic vaccination schedule for children aged 15 months (11).

A number of studies have targeted varicella morbidity and disease burden, as well as the cost-effectiveness and possible impact of vaccination (12-15). In addition to furnishing information on the dynamics and distribution of diseases, seroprevalence studies are a useful collaborative decision-making tool when it comes to the question of introducing vaccines $(3,16,17)$. In the case of vaccine-preventable diseases, such studies can also furnish relevant information on vaccination coverages, vaccine failures and loss of immunity.

This study sought to ascertain VZV antibody seroprevalence and its trend in the population of the Madrid Region, in the stage 
preceding inclusion of universal varicella vaccination in the vaccination schedule.

\section{MATERIAL AND METHODS}

This was a cross-sectional antibody seroprevalence study that included various diseases. For the purposes of our study, data on varicella were used.

Target study population: persons of both sexes aged 2 to 60 years, residing in the MAR, who attended blood collection centres in the period during which the field work was carried out, were enrolled (September 1999 to April 2000).

Sampling framework: outpatient blood-collection centres belonging to the Madrid Health Institute.

Age groups: 2 to 60 years $(2-5,6-10,11-15,16-20,21-30$, 31-40 and 41-60 years). Seven independent samples were obtained, corresponding to each of these age groups. In the case of varicella, we dispensed with the last-mentioned age group since there are no significant changes in the prevalence of antibody to varicella after the age of 40 years. A sample size of 300 individuals per age group was estimated, thus making a total sample of 2,100 individuals. Taking into account the non-response rate reported in an earlier survey (31.3\%), the number of persons who had to be contacted totalled 3,057. Subjects were selected using two-stage cluster sampling with stratification of stage-one units:

- Stratification: by Health Area and sex for each of the six age groups considered. Allocation of blood-extraction centres per stratum: proportional to the population assigned to each area on the basis of health cards.

- The number of individuals selected at each centre was initially constant in each age group. At each centre, individuals were selected using random start systematic sampling separately for each age group.

Variables:

- Identification data: on interviewees (name, address, telephone number, age, sex and place of birth) and blood-extraction centres (name, health area, town and district).

- Data on individuals who refused to participate: age, sex, surface area of home and educational level.

- Socio-economic variables: interviewee's educational level (or that of the father and mother in the case of children aged 2 to 15 years) and occupations of the interviewee and main provider of financial support. Measurement of educational level was based on the classification and coding used by the Madrid Regional Statistics Department (Departamento de Estadística de la Comunidad de Madrid, Consejería de Economía, 1993). Occupation was compiled in accordance with the National Classification of Occupations (Clasificación Nacional de Ocupaciones - CNO-946).

- Other variables of interest: place of birth, surface area of home, number of cohabitants in the household, number of interviewee's older and younger siblings, number of children, school attendance (only in subjects under the age of 6 years).

- History of diseases or exposures of interest: immunodepression-related health problems and diseases targeted for analysis.

To validate the sample, the sampling distribution of the variables of educational and socio-economic level was compared to the distribution of these variables in the Madrid Region Public Health Survey, a population-based survey conducted at about the same time (first half of 2001). The distribution of educational level was likewise compared to that of the 1996 Municipal Voters' Roll.

Surveys were conducted by interviewers at blood-extraction centres or by telephone, and study serum samples were taken by nursing staff employed at the centres.

Laboratory techniques:

Determination of IgG specific to varicella virus obtained from cell culture. Technique: commercially available indirect ELISA (Enzygnost, Dade Behring, Germany).

Interpretation of results: qualitative and quantitative assessment. Quantification of results, expressed in international milliunits per millilitre $(\mathrm{mUI} / \mathrm{ml})$, was performed using a standardised one-point procedure ( $\alpha$-method). According to the manufacturer's definition, any increase in net absorbance of over 0.1 is to be deemed positive; under optimal conditions, this value equals $50 \mathrm{mIU} / \mathrm{ml}$.

Serological determinations were performed at the Madrid Region Public Health Laboratory.

Prevalence of varicella antibody was determined by age group. Antibody prevalence was compared to that obtained in the 1993 seroprevalence study, by age group, using comparison of proportions for independent samples.

We calculated the predictive value positive of history of varicella.

The association between antibody prevalence or non-prevalence and the respective study variables was obtained. We used the Student's t-test for independent samples in the case of quantitative variables, and the $\chi^{2}$ test for qualitative variables.

To assess the independent association between the presence of VZV antibody and the study variables, two binary logistic regression models were fitted, one for individuals under the age of 6 years (the age group in which incidence is highest), and the other for the whole sample, taking the presence of antibodies against varicella as the outcome variable, and as covariables, those in which a statistically significant association $(\mathrm{p}<0.05)$ was observed with antibody prevalence, and those that, despite not displaying said association, were considered relevant for transmission of infection.

\section{RESULTS}

A total of 2,131 subjects were included. The non-response rate was $20.4 \%$ (18\% in men and $22.7 \%$ in women). The main reason for non-response was lack of interest in the survey combined with expressed refusal to collaborate, which accounted for $41.4 \%$ of total non-response. Fear of blood collection was the second leading reason (21.3\%). In case of variables concerning of educational level and socio-economic level, no significant differences were observed as against the Madrid Region Public Health Survey and Municipal Voters' Roll.

Estimated prevalence of varicella antibody in the population aged 2 to 40 years was $90.2 \%$ (95\% CI: 89.6 - 92.2). The prevalence of individuals with varicella antibody increased progressively from 2 to 11 years, at which age prevalence rose to $90 \%$ (Table 1). Thereafter, prevalence continued to rise steadily, though 
Table 1. Prevalence of varicella antibodies by age group

\begin{tabular}{|l|c|c|c|c|}
\hline Age (years) & $\mathbf{n}$ & Prevalence & \multicolumn{2}{|c|}{$95 \% \mathbf{C l}$} \\
\hline $\mathbf{2}$ to $\mathbf{5}$ & $\mathbf{2 7 9}$ & 44.2 & 38.4 & 50.0 \\
\hline $\mathbf{6}$ to $\mathbf{1 0}$ & 308 & 80.5 & 76.1 & 84.9 \\
\hline $\mathbf{1 1}$ to $\mathbf{1 5}$ & 310 & 93.8 & 91.1 & 96.5 \\
\hline $\mathbf{1 6}$ to $\mathbf{2 0}$ & 313 & 93.9 & 91.2 & 96.6 \\
\hline $\mathbf{2 1}$ to $\mathbf{3 0}$ & 317 & 95.8 & 93.6 & 98.0 \\
\hline $\mathbf{3 1}$ to $\mathbf{4 0}$ & $\mathbf{3 0 2}$ & 97.4 & 95.6 & 99.2 \\
\hline Total & 1829 & 90.9 & 89.6 & 92.2 \\
\hline
\end{tabular}

$\mathrm{Cl}$, confidence interval

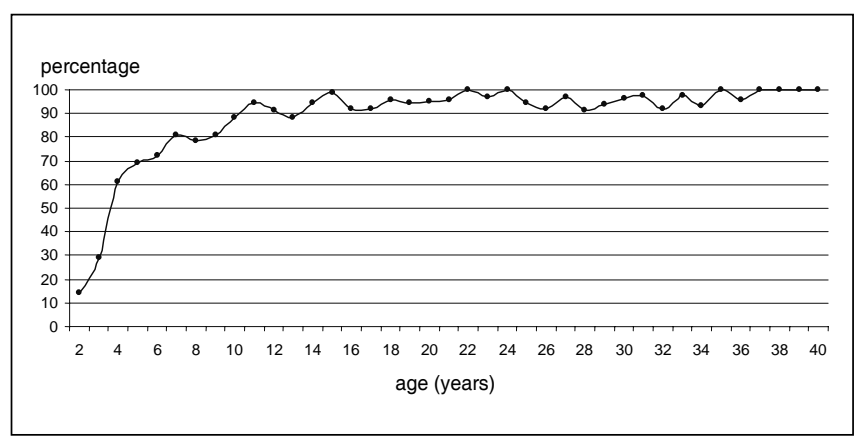

Fig. 1. The prevalence of varicella antibodies by age. The prevalence is expressed as a percentage. At 11 years prevalence reaches $90 \%$, and since then, it will increase steadily.

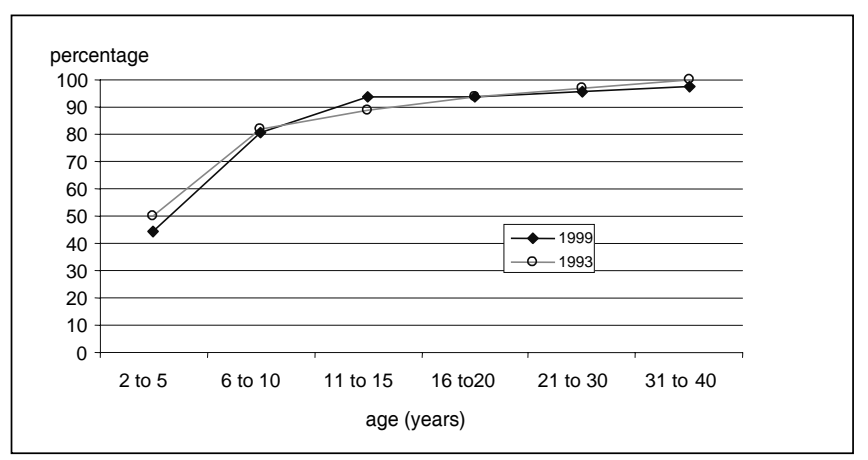

Fig. 2. The prevalence of varicella antibodies by age groups, comparison of seroepidemiologic surveys, 1993 and 1999, done in Madrid. The prevalence is expressed as a percentage. Results are similar for both surveys.

much more slowly, so that close on $100 \%$ of persons reached adult age with positive antibodies (Fig. 1). No significant differences in prevalence were observed between the sexes. Of the subjects with positive history of varicella, $98.4 \%$ were positive.

In the comparison of antibody prevalence between 1993 and 1999, no statistically significant differences were detected (Fig. 2).

After the bivariate analysis, age (OR $=1.18$; 95\% CI: 1.15 -1.21) and history of varicella (OR = 53.9; 95\% CI: 32.1 - 90.4) were used as covariables in the logistic regression model of the entire sample. In the model fitted in the under-7 age group, the covariables were age (OR $=1.71$; 95\% CI: $1.13-2.59$ ), history of varicella (OR $=65.1$; 95\% CI: $24.8-170.9)$, and school attendance, which displayed a strong and almost significant $(\mathrm{p}=0.057)$ association with the dependent variable $(\mathrm{OR}=4.6$; 95\% CI: 0.96 - 21.9).

\section{DISCUSSION}

This study took place within the overall context of a crosssectional, general seroprevalence study undertaken in the Madrid Autonomous Region in 1999.

No relevant differences were observed in the variables chosen for validation against the Madrid Region Public Health Survey and Municipal Voters' Roll. One limitation of the study was the absence of population that made no use of public health services (even though all inhabitants enjoy access to such services in Spain). The non-response rate was significantly lower than that reported in the 1993 seroprevalence survey (31.3\%).

In a situation of absence of vaccination, such as that prevailing in Spain in 1999, the proportion of susceptible individuals was observed to remain stable in the period between the 1993 and 1999 surveys.

The seroprevalence profile observed agrees with the results reported by other studies conducted in Spain $(18,19)$ and other European regions $(3,20,21)$, though in other areas a very high prevalence was reached at lower ages $(16,22,23)$. In a situation where there is no vaccination, it seems that permanent contact with the wild virus leads to the presence of antibody being maintained with age, since no decrease in antibodies was observed at adult age. This may be important because the booster effect attributable to sustained contact with the virus is thought by some to reinforce immunity and cause herpes zoster incidence to remain stable (24).

As was to be expected, the strength of the association with history of having suffered from varicella was very high. Furthermore, in line with the results obtained in other studies $(19,25)$, the predictive value positive of history of varicella was also very high.

Among children under the age of 7 years, there was an almost significant association with school attendance, which seems logical in view of the close contact among children in junior and nursery schools and the extreme contagiousness of the disease. No significant association was observed with other factors, such as the surface area of the home, number of cohabitants, educational level (of the patient or parents), or social class, which goes to confirm that the disease affects the whole population to an equal extent.

Varicella is an extremely contagious disease, and vaccination against it has been a very controversial topic (5). The vaccine appears to be effective in reducing both the incidence of the disease $(26,27)$ and its complications (10), which, coupled with the high vaccination coverages attained in Spain, would result in a high immunised-population percentage. Some of the objections raised to the vaccine are that, though it is highly effective, its effectiveness is nevertheless not total, and indeed there have been descriptions of vaccine failures leading to outbreaks $(24,28)$. An additional concern lies in the possibility that the age of disease presentation may be shifted towards adulthood, when it is more severe $(5,24$, 29). It is also not clear just how universal vaccination would affect the epidemiology of herpes zoster (30). 
In Spain, vaccination is recommended by the Ministry of Health \& Consumer Affairs in children aged 10 to 14 years, though universal vaccination at 12 months has been urged by some scientific societies since 1999 (31) and nothing is known about the possible effect of administration of vaccine at a private level in the interim. The MAR recently introduced vaccination for children aged 15 months into its systematic vaccination schedule (11). This is the reason for planning and conducting of subsequent studies on seroprevalence, vaccination coverages, and the effectiveness of varicella vaccine. Such studies will assess the influence of vaccine introduction on the dynamic of the disease and of herpes zoster, and to detect pockets of susceptible individuals. Similarly, use of other sources, such as sentinel medical practitioner networks or individualised case reports, could furnish relevant information in the post-vaccination stage.

\section{REFERENCES}

1. Whitley RJ. Varicella-Zoster Virus. In: Mandell GL, Bennett JE, Dolin R, editors. Principles \& practice of infectious diseases. 5th ed. Philadelphia: Churchill Livingstone; 2000. p. 1580-6.

2. Vázquez M. Varicella infections and varicella vaccine in the 21st century. Pediatr Infect Dis J. 2004 Sep;23(9):871-2.

3. Vyse AJ, Gay NJ, Hesketh LM, Morgan-Capner P, Miller E. Seroprevalence of antibody to varicella zoster virus in England and Wales in children and young adults. Epidemiol Infect. 2004 Dec;132(6):1129-34.

4. Brisson M, Edmunds WJ. Epidemiology of varicella-zoster virus in England and Wales. J Med Virol. 2003;70 Suppl 1:S9-14.

5. Cortés M, Pereira J, Peña-Rey I, Génova R, Amela C. Disease burden due to vaccinable diseases in the Spanish population aged less than 15 years old. Gac Sanit. 2004 Jul-Aug;18(4):312-20. (In Spanish.)

6. Asano Y. Varicella vaccine: the Japanese experience. J Infect Dis. 1996 Nov;174 Suppl 3:S310-3.

7. American Academy of Pediatrics, Committee on Infectious Diseases. Recommendations for the use of live attenuated varicella vaccine. Pediatrics. 1995 May;95(5):791-6.

8. Prevention of varicella: Recommendations of the Advisory Committee on Immunization Practices (ACIP). Centers for Disease Control and Prevention. MMWR Recomm Rep. 1996 Jul 12;45(RR-11):1-36.

9. Centers for Disease Control and Prevention. Decline in annual incidence of varicella-selected states, 1990-2001. MMWR Morb Mortal Wkly Rep. 2003 Sept 19;52(37):884-5.

10. Nguyen HQ, Jumaan AO, Seward JF. Decline in mortality due to varicella after implementation of varicella vaccination in the United States. N Engl J Med. 2005 Feb 3;352(5):450-8.

11. Health and Consumption Council. Ruling 1869/2006 updating the calendar of regular vaccinations of children in the Municipality of Madrid. Bol Of Comun Madr. 2006 Oct 24;(253):5-6. (In Spanish.)

12. Peña-Rey I, Pérez-Farinós N, Cortés-García M, Amela-Heras C. Costeffectiveness of varicella vaccination in Spanish adolescents. Gac Sanit. 2004 Jul-Aug;18(4):287-94. (In Spanish.)

13. Gil A, San Martín M, Carrasco P, González A. Epidemiology of severe varicella-zoster virus infection in Spain. Vaccine. 2004 Sep 28;22(2930):3947-51.
14. Brisson M, Edmunds WJ. Varicella vaccination in England and Wales: cost-utility analysis. Arch Dis Child. 2003 Oct;88(10):862-9.

15. Coudeville L, Brunot A, Giaquinto C, Lucioni C, Dervaux B. Varicella vaccination in Italy: an economic evaluation of different scenarios. Pharmacoeconomics. 2004;22(13):839-55.

16. Mossong J, Putz L, Schneider F. Seroprevalence and force of infection of varicella-zoster virus in Luxembourg. Epidemiol Infect. 2004 Dec;132(6):1121-7.

17. Kanra G, Tezcan S, Badur S; Turkish National Study Team. Varicella seroprevalence in a random sample of the Turkish population. Vaccine. 2002 Jan 31;20(9-10):1425-8.

18. Seroepidemiological study: the situation in Spanish concerning diseases preventable throught vaccination. Madrid: Instituto de Salud Carlos III; 1996. (In Spanish.)

19. Diez-Domingo J, Gil A, San Martín M, González A, Esteban J, Baldó JM, et al. Seroprevalence of varicella among children and adolescents in Valencia, Spain. Reliability of the parent's reported history and the medical file for identification of potential candidates for vaccination. Hum Vaccin. 2005 Sep-Oct;1(5):204-6.

20. Khoshnood B, Debruyne M, Lançon F, Emery C, Fagnani F, Durand I, et al. Seroprevalence of varicella in the French population. Pediatr Infect Dis J. 2006 Jan;25(1):41-4.

21. Gabutti G, Penna C, Rossi M, Salmaso S, Rota MC, Bella A, et al; Serological Study Group. The seroepidemiology of varicella in Italy. Epidemiol Infect. 2001 Jun;126(3):433-40.

22. De Melker H, Berbers G, Hahné S, Rümke H, van den Hof S, de Wit A, et al. The epidemiology of varicella and herpes zoster in the Netherlands: implications for varicella zoster virus vaccination. Vaccine. 2006 May 1;24(18):3946-52.

23. Wutzler P, Färber I, Wagenpfeil S, Bisanz H, Tischer A. Seroprevalence of varicella zoster virus in the German population. Vaccine. 2001 Oct 12;20(1-2):121-4

24. Edmunds WJ, Brisson M. The effect of vaccination on the epidemiology of varicella zoster virus. J Infect. 2002 May;44(4):211-9.

25. Dayan GH, Panero MS, Debbag R, Urquiza A, Molina M, Prieto S, et al. Varicella seroprevalence and molecular epidemiology of varicella zoster virus in Argentina, 2002. J Clin Microbiol. 2004 Dec;42(12):5698-704.

26. Vázquez M, LaRussa PS, Gershon AA, Steinberg SP, Freudigman K, Shapiro ED. The effectiveness of the varicella vaccine in clinical practice. N Engl J Med. 2001 Mar 29;344(13):955-60.

27. Vázquez M, LaRussa PS, Gershon AA, Niccolai LM, Muehlenbein CE, Steinberg SP, et al. Effectiveness over time of varicella vaccine. JAMA. 2004 Feb 18;291(7):851-5.

28. Lee BR, Feaver SL, Miller CA, Hedberg CW, Ehresmann KR. An elementary school outbreak of varicella attributed to vaccine failure: policy implications. J Infect Dis. 2004 Aug 1;190(3):477-83.

29. Welsby PD. Chickenpox, chickenpox vaccination, and shingles. Postgrad Med J. 2006 May;82(967):351-2.

30. Hambleton S. Chickenpox. Curr Opin Infect Dis. 2005 Jun;18(3):23540.

31. Bernaola Iturbe E, Giménez Sánchez F, Baca Cots M, de Juan Martín F, Díez Domingo J, Garcés Sánchez M, et al.; Spanish Association of Pediatrics. Vaccination schedule of the Spanish Association of Pediatrics: recommendations 2006. An Pediatr (Barc). 2006 Jan;64(1):74-7. (In Spanish.) 